\title{
PROJETO RECICLANDO: AÇÃO AMBIENTAL DE UMA SALA VERDE UTILIZANDO UM VIVEIRO EDUCADOR
}

\author{
J. M. V. Fonseca ${ }^{1}$, R. C. Frenedozo ${ }^{2}$, G. G. Landa ${ }^{3}$ \\ ${ }^{1}$ Coordenação de Formação Geral - CEFET-MG/Campus V - josemaria@div.cefetmg.br \\ ${ }^{2}$ Programa de Pós-Graduação em Ensino de Ciências - Universidade Cruzeiro do Sul, \\ rita.frenedozo@cruzeirodosul.edu.br \\ ${ }^{3}$ Doutor em Ecologia, Conservação e Manejo de Vida Silvestre- gioguimaraes@yahoo.com.br
}

Enviado em junho/2012 e aceito em janeiro/2013

\section{RESUMO}

A sala verde é um espaço que proporciona, à população em geral, o acesso a informações e materiais de educação ambiental através de cursos, palestras, oficinas, vivências, e outros. Em Divinópolis - MG, a sala verde Frei Paulino desenvolve um trabalho de educação ambiental que objetiva informar e sensibilizar, a comunidade, alunos e professores do ensino fundamental das escolas municipais, sobre a questão do lixo urbano. As ações educativas foram desenvolvidas utilizando a estrutura do viveiro florestal permitindo um trabalho sistemático de informações a respeito do desmatamento, consumismo desnecessário, manejo correto do lixo urbano, e recolhimento da sucata ferrosa. No período decorrente desta avaliação foram atendidas 148 escolas com a participação de 8.263 alunos/professores, tendo sido retirado do meio ambiente $35.717,9 \mathrm{Kg}$ de sucata ferrosa. Os resultados confirmam que o viveiro educador é, sem dúvida, uma boa estratégia para se fazer educação ambiental.

PALAVRAS-CHAVE: Educação ambiental; sala verde; lixo urbano

\section{RECYCLING PROJECT: ENVIRONMENTAL ACTION OF A GREEN ROOM USING AN EDUCATOR NURSERY}

\begin{abstract}
The green room is a space that provides to the citizen the access to information and materials of environmental education through courses, lectures, workshops, experiences, and others. In Divinópolis - Minas Gerais State, the green room Frei Paulino develops a work of environmental education that aims to inform and sensitize the community, elementary school students and teachers of municipal schools, on the issue of urban garbage.
\end{abstract}

Educational actions were developed using the structure of the nursery forest allowing a systematic work of information regarding, deforestation, the correct handling of unnecessary consumerism, urban waste and scrap gathering. In the period of this evaluation were met 148 schools attended by pupils/teachers, 8,263 having been taken from the environment of iron scrap $35.717,9 \mathrm{Kg}$. The results confirm that the nursery educator is undoubtedly a good strategy for environmental education.

KEYWORDS: environmental education; green room; urban garbage 


\section{INTRODUÇÃO}

Entende-se por Sala Verde um espaço definido situado dentro de uma Instituição, o qual será dedicado ao delineamento e desenvolvimento de atividades de caráter educacional voltadas à temática ambiental, tendo como uma das principais ferramentas a divulgação e a difusão de publicações sobre Meio Ambiente produzida e/ou fornecidas pelo Ministério do Meio Ambiente, através do CID Ambiental. Este projeto foi desenvolvido desde 2002, coordenado pela Diretoria de Educação Ambiental (DEA), que oferece materiais e orientação para trabalhar a educação ambiental em qualquer lugar do país. O projeto surgiu objetivando a atender ao público que visitava as dependências do Centro de Informação e Documentação Ambiental (CID Ambiental) em busca de materiais, publicações e informações para que pudesse utilizar nos trabalhos de Educação Ambiental a serem desenvolvidos em seu município. A partir de 2004 o projeto passou por uma reformulação quanto ao atendimento, adquirindo um caráter Político Pedagógico, estimulando a implantação de um espaço de informação e formação ambiental ("Sala Verde"), proporcionando, à população em geral, o acesso a informações e materiais de educação ambiental através de cursos, palestras, oficinas, vivências, e outros. Atualmente existem 390 salas verdes em todo o país (SANTOS; PARDO, 2011).

Atendendo às normas exigidas pelo MMA, em maio de 2007 foi aprovado o projeto da Sala Verde Frei Paulino, com apoio da Secretaria Municipal de Educação (SEMED), Secretaria Municipal de Meio Ambiente e Planejamento Urbano (SEMMAPU) e Secretaria de Esporte e Lazer (SEL), do município de Divinópolis em Minas Gerais.

Em fevereiro de 2009 a sala verde Frei Paulino iniciou o Projeto Reciclando, objeto desta pesquisa, que conta com a participação de uma empresa privada, GERDAU - Aços Longos Divinópolis S/A, alguns órgãos públicos, IEF, EMATER, CEFET-MG e secretarias municipais.

Este projeto proporciona um trabalho que utiliza da estrutura de um viveiro florestal como forma de educação ambiental para crianças (MARANHÃO, 2006), pautando-se no projeto "Viveiro Educador" do Departamento de Educação Ambiental do MMA.

Esta pesquisa objetivou avaliar se o viveiro florestal, utilizado para os trabalhos que são desenvolvidos através do Projeto Reciclando, pode vir a ser considerado um Viveiro Educador que, segundo Brasil (2008), é um espaço que além da produção de mudas, deve desenvolver de forma intencional, processos que buscam ampliar as possibilidades de construção de conhecimento, possibilitando em seus procedimentos e práticas, reflexões que tragam o olhar crítico sobre questões relevantes para a Educação Ambiental.

\section{FUNDAMENTAÇÃO TEÓRICA}

A Conferência Intergovernamental de Educação Ambiental (EA) ocorrida em Tbilisi (1977) estabelece como objetivos fundamentais da EA, levar os indivíduos e a coletividade a compreender seu ambiente natural e o ambiente construído pelo homem, bem como incentivá-los na aquisição de conhecimentos, valores, comportamentos e habilidades práticas para participar da prevenção e da solução da gestão ambiental (DIAS, 2001; SOUZA, 2003).

Em 2011, o Brasil produziu 61,9 milhões de toneladas de lixo, sendo que 6,5 milhões de toneladas não foram coletadas (ABRELP, 2011) e acabaram em rios, córregos e terrenos 
baldios. Apesar das informações prestadas pelos meios de comunicação em relação ao destino correto do lixo, muitos cidadãos não conseguem perceber a importância de avaliar e participar de ações que venham favorecer o meio em que vivem. Para a sociedade consumista - lixo não representa um problema, sobretudo porque o incômodo de tê-lo acaba no momento em que é recolhido pelo caminhão coletor, não dando a devida atenção ao seu destino final.

O consumo desenfreado, a produção industrial descompromissada com a preservação ambiental, o acúmulo de produtos descartáveis e de resíduos, geram uma grande agressão ao meio ambiente. Neste contexto, torna-se relevante encontrar alternativas para a gestão dos resíduos sólidos urbanos no meio ambiente e gerar programas de Educação Ambiental.

O tratamento que damos ao nosso lixo tem recebido crescente atenção (MAZZINI, 1997; GONÇALVES, 2000; LAYARGUES, 2002; DIAS, 2003), tal fato justifica programas de educação ambiental que contribuam para formar uma consciência ambiental que faça emergir, de cada cidadão, a necessidade do manejo adequado do seu lixo (DIAS, 2003; ZANETI, 2003; SOARES, 2007; REIS et al, 2008; THOMAZ-JÚNIOR, 2009; SANTOS et. al, 2010) e diminuição do hábito consumista. Porém, alguns programas de educação ambiental, tomando como exemplo o Projeto Escola (criado em 1993 pela Reynolds Latasa), limitam-se à coleta seletiva de lixo para posterior venda, gerando uma receita para o sustento do projeto ou ganho de equipamentos oferecidos pela empresa de reciclagem.

Tais projetos são válidos por trazerem benefícios para as escolas, indústrias e o meio ambiente, porém, fica reduzida à reciclagem sem reflexão sobre o consumismo em suas dimensões econômica, política, social e cultural, não conseguindo desenvolver, nas pessoas envolvidas, atitudes e comportamentos que possam levar à compreensão das causas dos hábitos consumistas (LAYRARGUES, 2002, p.212) alimentado pelos interesses econômicos e pelos efeitos da mídia no consumo.

\section{$>$ Viveiro florestal X Viveiro Educador X Educação Ambiental}

Segundo Paiva (2000), um viveiro é um espaço estruturado, com suas próprias características, onde há a produção, manejo e proteção de mudas, até que estas tenham idade e tamanho suficientes para resistirem em condições reais de campo.

Viveiros Florestais são áreas com um conjunto de benfeitorias e utensílios, em que se empregam técnicas visando obter o máximo da produção de mudas (MACEDO, 1993).

Um viveiro florestal pode ser considerado um Viveiro Educador (BRASIL, 2008) quando além da produção de mudas, existe a intenção de utilizá-lo como espaço de aprendizagem (MARANHÃO, 2006; LEMOS; MARANHÃO, 2008).

Viveiros Educadores são espaços de produção de mudas de espécies vegetais onde, além de produzi-las, desenvolvem-se de forma Intencional, processos que buscam ampliar as possibilidades de construção de conhecimento, exercitando em seus procedimentos e práticas, reflexões que tragam em seu bojo, o olhar crítico sobre questões relevantes para a Educação Ambiental como: ética, solidariedade, responsabilidade socioambiental, inclusão social, recuperação de áreas degradadas entre outras possibilidades. (BRASIL, 2008 P.10).

A relevância do estudo fundamenta-se em, sendo avaliada positivamente a utilização do viveiro florestal do Projeto reciclando, como Viveiro Educador e estratégia de educação 
ambiental, tornar pública a experiência servindo de exemplo para outras escolas (MARANHÃO, 2006; LEMOS; MARANHÃO, 2008; LEITE, 2008; JUNIOR; VARGAS, 2010).

\section{METODOLOGIA}

Tomando como base a taxionomia apresentada por Vergara (2004), a pesquisa pode ser classificada como uma investigação descritiva, pois o estudo tem como objetivo descrever as práticas realizadas pelo Projeto Reciclando, para poder entender como é realizado o trabalho no viveiro florestal e permitir avaliar como um Viveiro Educador. Com relação à categoria, é um estudo de caso, pois é direcionado ao Projeto Reciclando, da sala verde Frei Paulino, que trabalha a educação ambiental utilizando um viveiro florestal.

Para o desenvolvimento da pesquisa foram feitas observações diretas das duas ações educativas desenvolvidas através do Projeto Reciclando, no período de fevereiro de 2009 a julho de 2011, e consultas documentais.

1a ação educativa: Trabalho realizado com as escolas municipais local.

Divinópolis é um município do Estado de Minas Gerais distante a $121 \mathrm{~km}$ da capital Belo Horizonte, ocupando uma área de $708.909 \mathrm{Km}^{2}$ com, 213.016 habitantes (IBGE, 2012), gerando em média 180 toneladas de resíduos sólidos urbanos por dia (RIOS, 2008).

Este volume de lixo produzido justifica a implantação de projetos com ações pedagógicas que enfoque a problemática dos resíduos sólidos e auxilie aos envolvidos a construírem conhecimentos, habilidades e valores necessários para tomar decisões responsáveis (SANTOS \& MORTIMER, 2000; SANTOS \& SCHNETZLER, 2003) em relação ao problema do lixo, bem como a implantação da coleta seletiva do lixo domiciliar, uma vez que ensinar sem dar subsídios para desenvolvimento das ações torna inviável qualquer projeto.

O trabalho de educação ambiental destinado às escolas municipais da região ocorre através de um agendamento prévio pela escola interessada. O processo ensino-aprendizagem, coordenado pela da equipe pedagógica da sala verde, se faz através de atividades com a participação de alunos e professores em práticas de germinação de sementes, compostagem, produção de mudas de árvores frutíferas e ornamentais.

As sementes são doadas pelo Instituto Estadual de Florestas - IEF e as orientações dadas por um agrônomo, do mesmo órgão, que trabalha com os professores e alunos, do plantio da semente até o processo final da muda, fazendo uso, sempre que possível, da reciclagem e reutilização de materiais.

No galpão de compostagem é demonstrado aos participantes o adequado tratamento no destino final do lixo, onde ocorre o processo biológico de compostagem, no qual, os microrganismos convertem a parte orgânica dos resíduos em material estável tipo húmus também conhecida como composto. Nesta etapa promove-se uma discussão sobre as ações negativas da queimada e desmatamento, em relação ao processo natural da reutilização da matéria.

No galpão da sementeira os participantes aprendem sobre os processos necessários para a germinação das sementes e plantio de mudas. Ao adquirir tamanho ideal, as mudas são levadas para o viveiro florestal para ser utilizada na segunda ação educativa do projeto. 
Após a atividade prática no viveiro florestal ocorre um intervalo para o lanche e, posteriormente, é ministrada uma palestra e a exposição de filmes abordando o contexto do destino correto do lixo urbano, o consumismo desnecessário, as consequências dos desmatamentos e a importância do plantio de árvores.

Durante as palestras os educadores da sala verde interagem com os participantes através de questionamentos e brincadeiras, buscando conhecer a percepção global da turma em relação ao tema trabalhado, de modo a utilizar uma linguagem adequada e vídeos infantis que atendam às necessidades do conhecimento apresentadas pelos alunos e professores.

Ao término dos trabalhos é feita uma proposta de atividades a serem realizadas em sala de aula (oficinas, filmes educativos, teatros, leitura, redações), sobre responsabilidade dos professores das diversas áreas do conhecimento, visando à continuidade dos conteúdos abordados na palestra e no filme exibido.

Para a realização das atividades propostas em sala de aula, a sala verde coloca à disposição, dos professores e alunos, um acervo bibliográfico cedido pelo MMA, filmoteca, computadores ligados à internet e orientação da equipe pedagógica.

2a ação educativa: troca voluntária de sucata ferrosa por mudas de árvores.

A sala verde Frei Paulino incentiva a troca voluntária de sucata ferrosa (muita das vezes descartadas em terrenos baldios, rios e córregos) por mudas de árvores ornamentais e frutíferas produzidas na primeira ação do projeto.

O cidadão interessado em obter as mudas, deve entregar na sala verde a sucata ferrosa recolhida. Ao receber a sucata, é feita a pesagem do material e o cidadão que solicita a troca é questionado sobre qual é o tipo de muda que deseja receber e o seu destino. Após a troca, o cidadão recebe informações sobre os cuidados necessários para o plantio.

A reciclagem tem a finalidade de aproveitar os resíduos para fabricar novos produtos, idênticos ou não aos que lhes deram origem (VALLE, 2002), sendo uma solução para a redução dos resíduos sólidos no ambiente, tendo solucionado muitos dos problemas gerados pela disposição inadequada de lixo e pela grande quantidade gerada.

Todas as ações diárias do Projeto Reciclando, desenvolvidas na sala verde Frei Paulino, são documentadas em um livro de controle das atividades realizadas, tendo sido utilizado na pesquisa documental para avaliar os resultados do projeto.

\section{RESULTADOS}

Os dados referentes às participações das escolas no viveiro florestal e às trocas de sucata ferrosa por mudas de árvores, no referido período, foram obtidos através de documentos cedidos pela direção da sala verde Frei paulino.

No ano de 2009, foram agendadas 61 visitas ao viveiro educador, atendendo 3261 alunos (Figura 1). As maiores demandas ocorreram em abril, maio e junho do primeiro semestre de 2009 e, no segundo semestre, no mês de agosto e setembro, fato justificado, informalmente por diretores e professores, da necessidade do apoio logístico para o transporte e alimentação dos alunos e da solicitação de dispensa do professorado que acompanha a turma, o que deve ser solicitado com antecedência junto à Secretaria de Educação. 


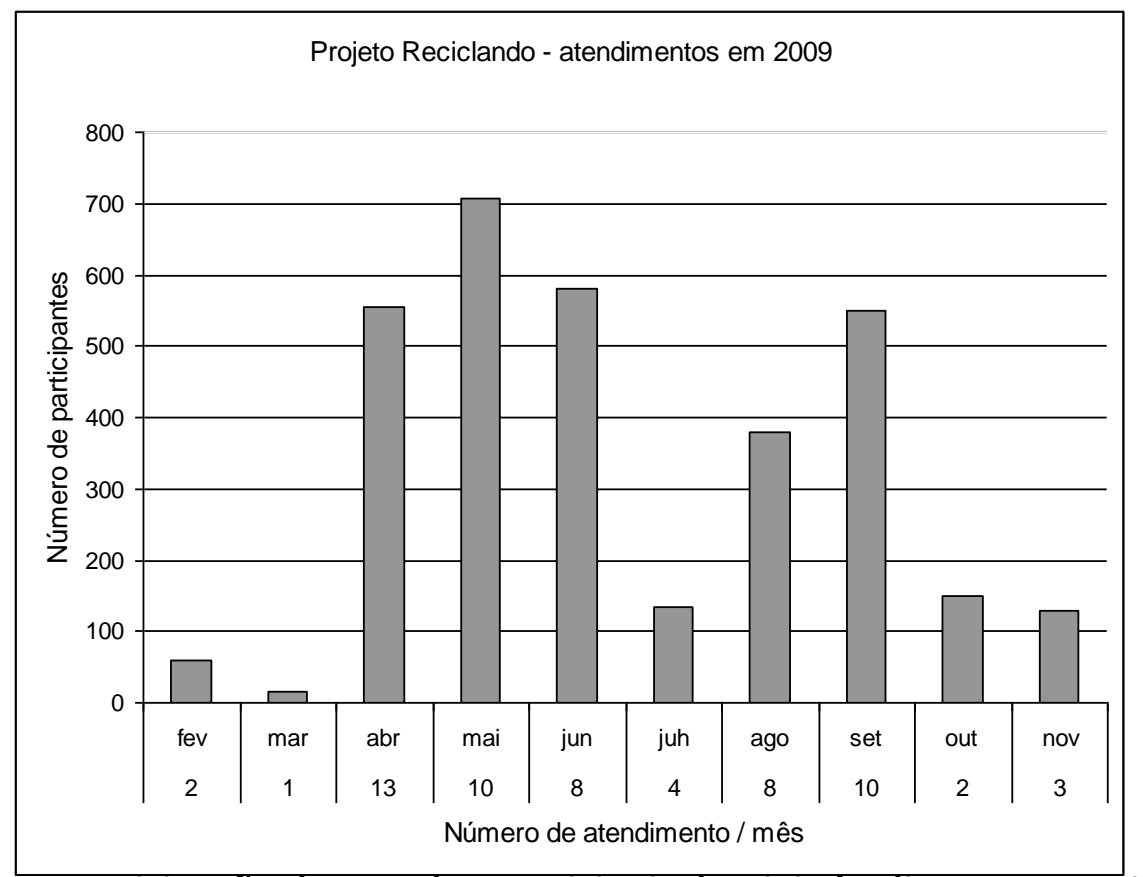

Figura 1 - Participação das escolas municipais de Divinópolis - MG na atividade do viveiro educador no ano de 2009.

Em 2010 foram agendadas 57 visitas, tendo sido atendidos 3228 alunos (Figura 2). Os dados revelam uma maior atividade em relação ao ano anterior, tanto no primeiro semestre quanto no segundo, sinalizando um maior interesse por parte das escolas, fato que talvez possa ser atribuído à divulgação dos trabalhos realizados, através dos professores participantes e da mídia local.

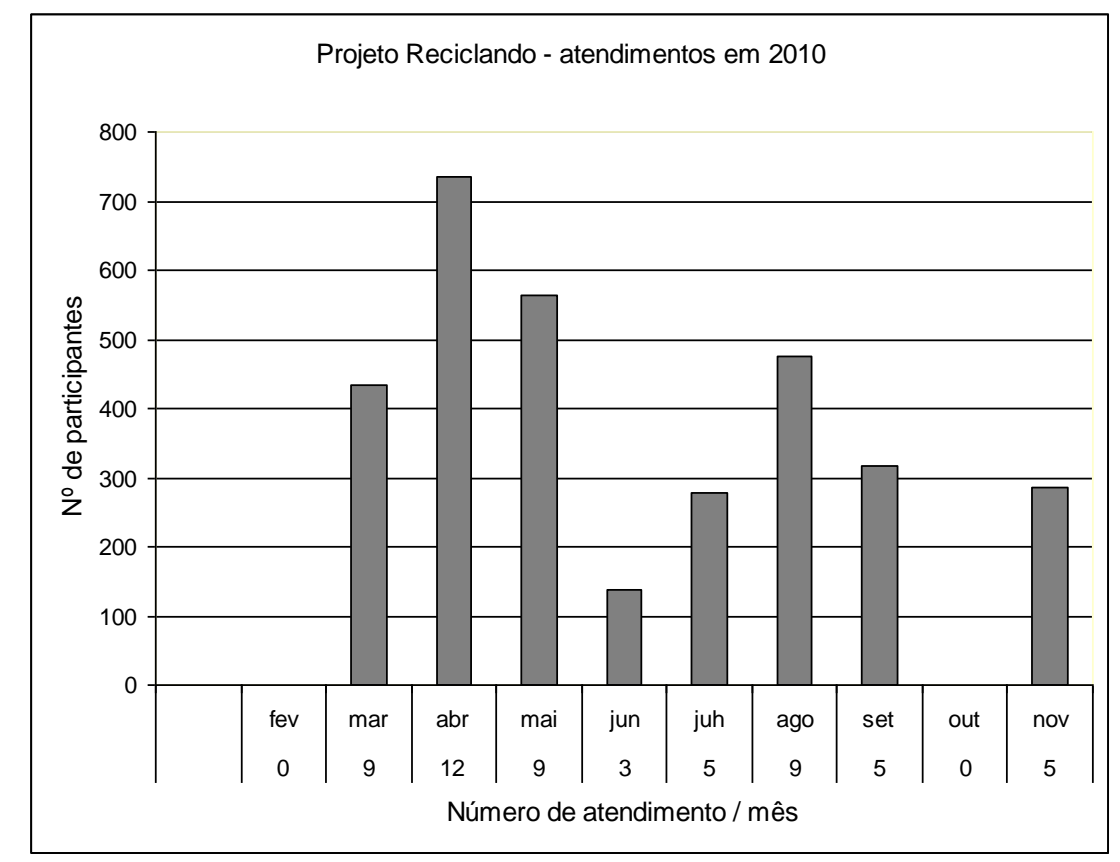

Figura 2 - Participação das escolas municipais de Divinópolis - MG na atividade do viveiro educador no ano de 2010 
No primeiro semestre de 20011 foram agendadas 30 visitas, tendo sido atendidos 1774 alunos (Figura 3), uma demanda superior em relação aos anos anteriores, no mesmo semestre. A menor demanda apresentada nos finais dos semestres foi justificada, também informalmente, devido ao acúmulo de serviço por parte dos professores (preparação de provas, material de recuperação, reuniões com a Secretaria de Educação, etc.), não se disponibilizando deslocar com os alunos.

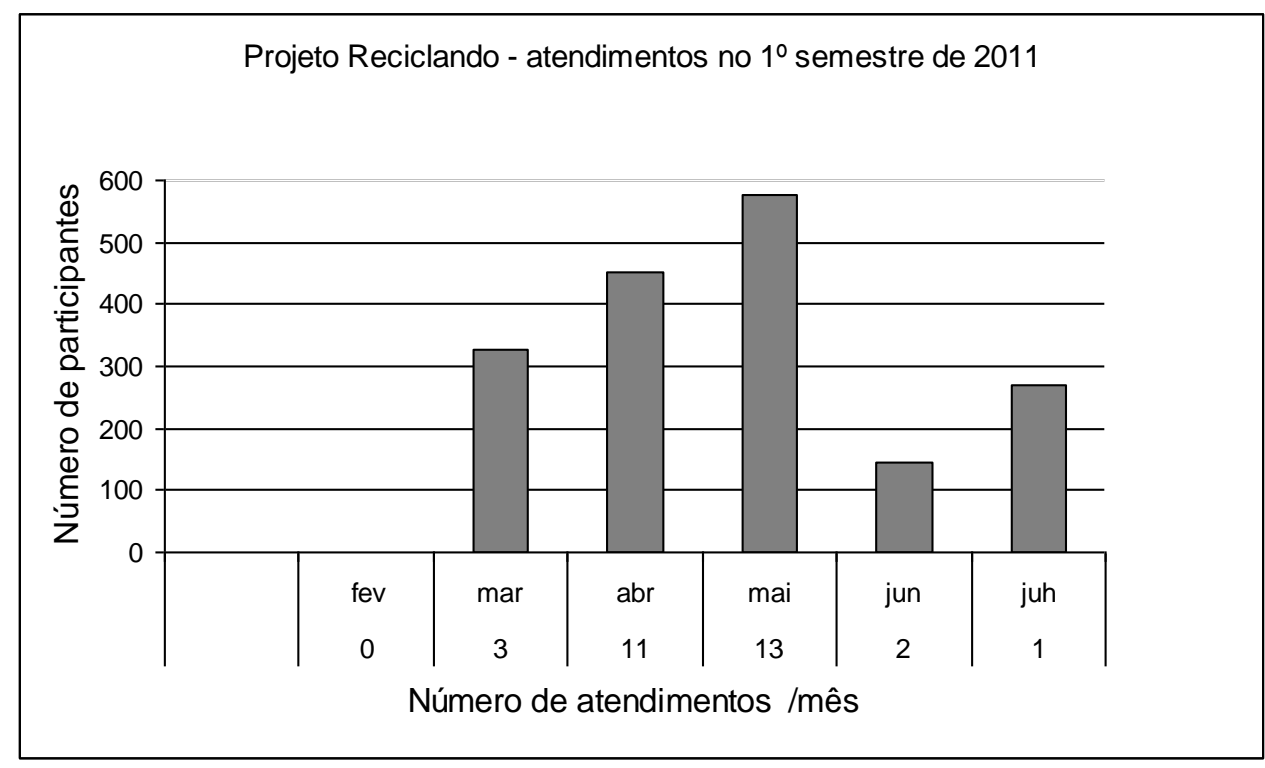

Figura 3 - Participação das escolas municipais de Divinópolis - MG na atividade do viveiro educador no ano de 2011

A interação entre os participantes, durante as palestras e atividades, permitiu avaliar, no ano de 2009, que o professor, em sua maioria, não apresentava razoável conhecimento em relação aos temas abordados na palestra e nos filmes exibidos, motivo pelo qual participava, ativamente, durante as apresentações de forma a receber informações relativas ao tema, ampliando sua bagagem cultural.

Essa avaliação serviu de fundamento para que a equipe da sala verde solicitasse junto a SEMED apoio para qualificação de professores da rede municipal de ensino na área de educação ambiental. Em resposta, a SEMED promoveu em fevereiro de 2010 o I seminário CTS para professores da rede municipal, com a participação do grupo de estudo CTS da Universidade Cruzeiro do Sul - SP, abordando conteúdos relativos às questões ambientais.

A participação no seminário propiciou a capacitação de professores permitindo elaborar e coordenar projetos de educação ambiental em suas escolas, abordando questão ambiental local e global, gerando projetos diversos: horta escolar, recomposição de áreas degradadas através do plantio de mudas produzidas no viveiro florestal da escola, trilhas interpretativas, ecoleitura e outros.

O projeto não apresenta uma pesquisa qualitativa que proporcione dados sobre a relevância das ações desenvolvidas no viveiro educador para a conscientização dos 
participantes em relação aos conteúdos trabalhados nas atividades: condições necessárias para o crescimento das árvores e sua importância para o meio ambiente; A importância do homem na transformação do meio em que vive e o que as interferências negativas têm causado à natureza; $O$ destino correto do lixo urbano; O consumismo e o meio ambiente e a Importância dos recursos tecnológicos na preservação do meio ambiente.

$\mathrm{O}$ trabalho realizado no Viveiro Educador tem gerado interesse por parte de algumas escolas, principalmente da zona rural, em implantá-lo na própria escola. Até o término da pesquisa, com auxilio da equipe técnica da sala verde Frei paulino, duas escolas iniciaram o projeto de um Viveiro educador, com a participação da escola e comunidade.

O projeto reciclando vêm cumprindo seu papel socioambiental e apresentando um crescimento vertiginoso no recolhimento de sucata ferrosa, por parte da população, ao ser trocado por mudas de árvores frutíferas e/ou ornamentais.

Em 2009, após a implantação do projeto, foram entregues 1382 mudas, em troca de sucata ferrosa, no período de abril a dezembro do referido ano (Figura 4), tendo maior preferência por mudas de árvores frutíferas (83\%). A pesagem total do material entregue foi de $8.600 \mathrm{Kg}$. A venda do material recolhido, para a empresa participante do Projeto, contribui para a manutenção do viveiro.

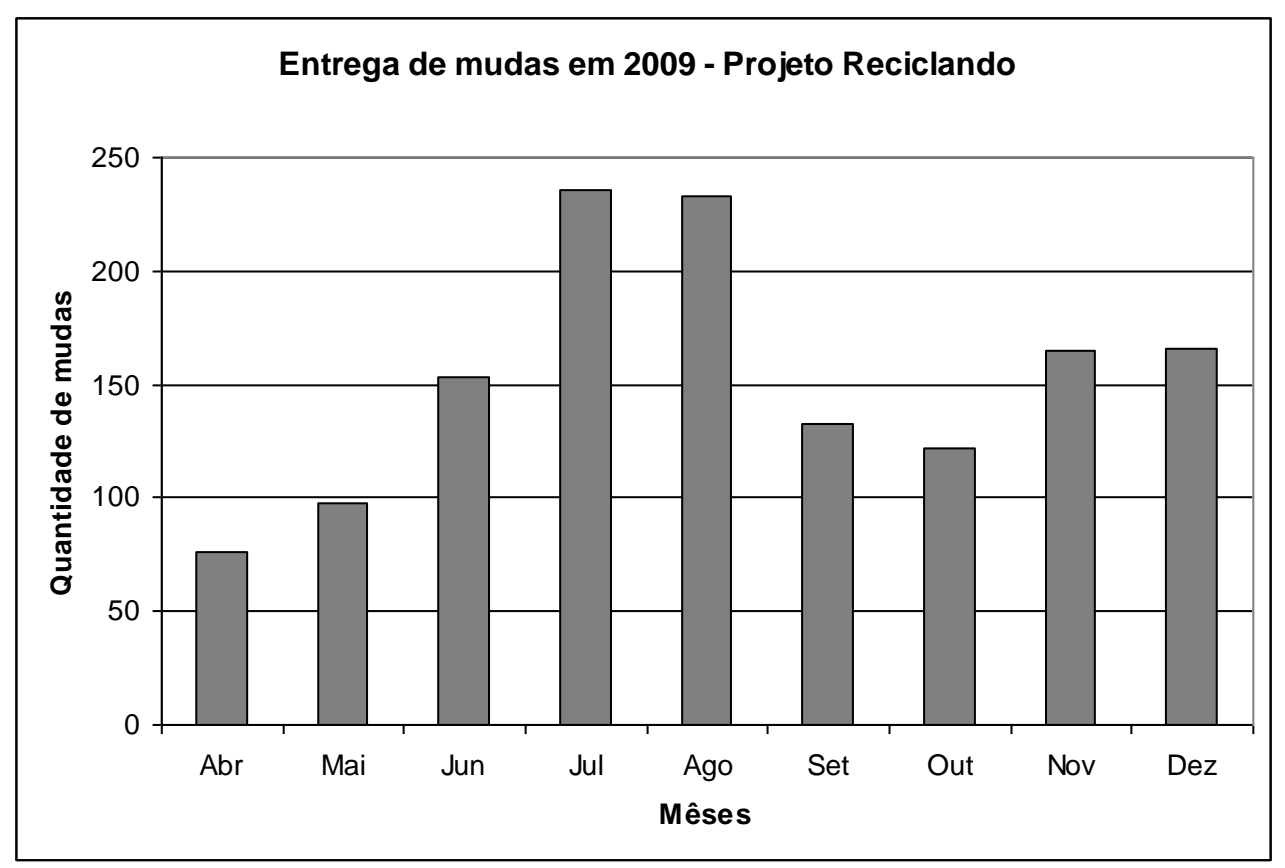

Figura 4 - Número de mudas entregues em 2009.

No ano de 2010 foram entregues 5377 mudas (Figura 5), resultado do recebimento de $12.335,6 \mathrm{Kg}$ de sucata ferrosa. A preferência por mudas de árvores frutíferas continuou maior (53,7\%), porém, apresentando uma "queda" em relação ao ano anterior (83 \%). 


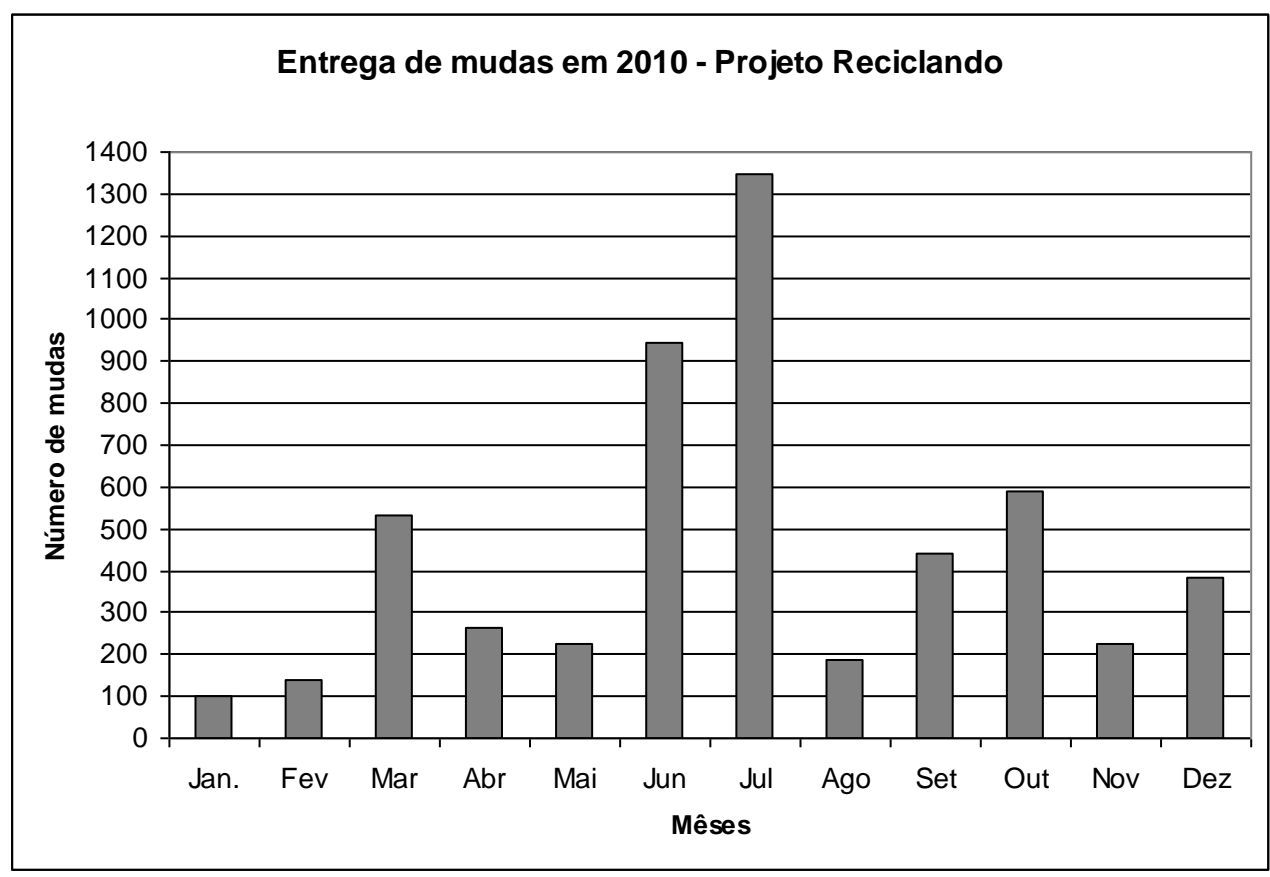

Figura 5 - Número de mudas entregues em 2010.

Até julho de 2011 haviam sido entregues 3440 mudas (Figura 6), resultado do recolhimento de $14.782,3 \mathrm{Kg}$ de sucata ferrosa. A preferência por mudas de árvores frutíferas continuou sendo mantida (83\%). No período decorrente desta avaliação foi recolhido um total de $35.717,9 \mathrm{Kg}$ de sucata ferrosa.

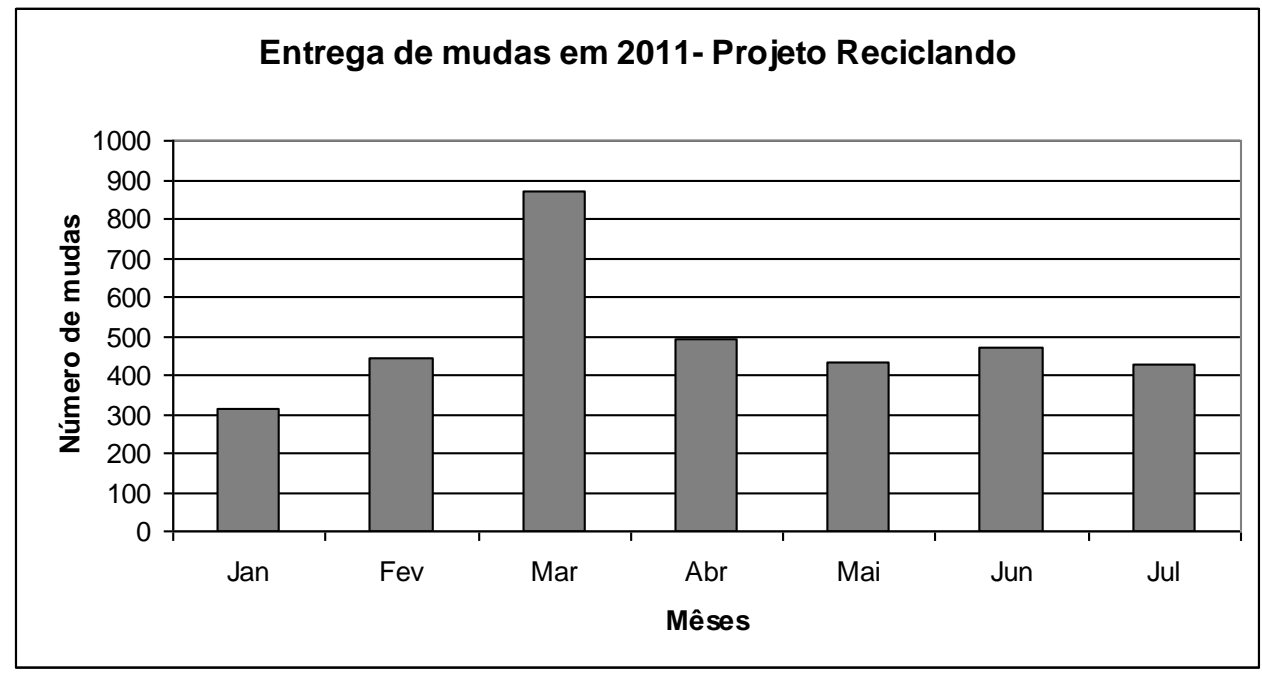

Figura 6 - Número de mudas entregues em 2011.

O recolhimento de sucata ferrosa, por parte da população, tem tornado, gradativamente, um hábito da comunidade divinopolitana, justificado pelo baixo valor pago 
por $\mathrm{Kg} /$ sucata e por facilitar a obtenção de mudas para compor jardins ou pomares, sem custo financeiro.

O processo educativo da sala verde Frei Paulino.

Para informar sobre a importância do cultivo e plantio de árvores, a reciclagem da matéria orgânica, a ação dos microorganismos presentes no solo, os cuidados necessários com a terra, os danos causados pelas queimadas e desmatamentos e outras ações, foram utilizados materiais pedagógicos adequados, coerente com a faixa etária dos alunos e nível escolar.

Por não ter ocorrido nenhuma avaliação qualitativa até o término da pesquisa, tornase necessário acreditar que, com as ações pedagógicas realizadas, seja possível transformar o comportamento (CARVALHO, 2004), pois segundo Tomazello (2012), os resultados de um processo educativo são conseqüências de uma ação prolongada por anos.

\section{CONCLUSÃO}

Após a realização desta pesquisa conclui-se que as ações desenvolvidas pela sala verde Frei Paulino, no município de Divinópolis-MG, através do Projeto reciclando, cumpre os objetivos propostos pelo projeto Viveiro Educador, assim como, ao possibilitar a troca de material ferroso por mudas de árvores, promove uma ação ambiental que contribui significativamente para a retirada da sucata ferrosa do meio ambiente, muita das vezes jogado em áreas comprometedoras.

Creio que a divulgação deste trabalho venha servir de incentivo para o surgimento de novos projetos de Viveiro Educador em escolas públicas de ensino.

\section{REFERÊNCIAS BIBLIOGRÁFICAS}

1. ABRELP - Panorama dos resíduos sólidos no Brasil. 2011 In: www.abrelpe.org.br Acessado em: 18 de outubro 2011.

2. BRASIL. Ministério do Meio Ambiente. Secretaria de Articulação Institucional e Cidadania Ambiental. 2008 Viveiros educadores plantando a vida. Brasília, DF: MMA, Departamento de Educação Ambiental, 84p.

3. CARVALHO, I. Educação Ambiental: a formação do sujeito ecológico. São Paulo: Cortez, 2004.

4. DIAS, G. Educação ambiental: princípios e práticas. 7. ed. São Paulo: Gaia, 2001.

5. DIAS, S. Avaliação de programas de educação ambiental voltados para o gerenciamento dos resíduos sólidos urbanos. Tese de doutorado apresentada ao Departamento de Saúde Ambiental da Faculdade de Saúde Pública da Universidade de São Paulo - Feira de Santana 2003.

6. GONÇALVES, M. Territorialização do trabalho informal: um estudo a partir dos catadores de papel/papelão e dos camelôs em Presidente Prudente (SP). 2000. 167 f. Dissertação 
(Mestrado em Geografia) - Faculdade de Ciências e Tecnologia, Universidade Estadual Paulista, Presidente Prudente.

7. IBGE - Instituto Brasileiro de Geografia e Estatística. Estimativas de População. Disponível em: <http://www.ibge.gov.br> Acesso em: 23/02/2012

8. JUNIOR, A. J. V; VARGAS, I. A. Plantas Medicinais e Conhecimento Tradicional Quilombola: um diálogo com a educação ambiental. Revista Eletrônica da Associação dos Geógrafos Brasileiros - Seção Três Lagoas/MS - no 12 - Ano 7, Novembro 2010. In: http://www.cptl.ufms.br/geo/revista-geo/Revista/revista12/Nova\%20pasta/7.pdf. Acessado em 24/03/2012

9. LAYRARGUES, P. P. O cinismo da reciclagem: o significado ideológico da reciclagem da lata de alumínio e suas implicações para a educação ambiental. In: Loureiro, Carlos.; Layargues, Philippe.; Castro, Ronaldo. (Orgs.) Educação ambiental: repensando o espaço da cidadania. São Paulo: Cortez, 2002, p.179-220.

10. LEITE, T. V. P. (2008). Quando um viveiro florestal torna-se um viveiro educador: estudode caso em uma escola classe do Distrito Federal. Dissertação de Mestrado em CiênciasFlorestais, Publicação PPGEFL.DM-106/08, Departamento de Engenharia Florestal,Universidade de Brasília, Brasília, DF, 78p.

11. LEMOS, G.N; MARANHÃO, R. R. O Viveiro Educador como espaço para Educação Ambiental. ambientaIMENTEsustentable. Xulho-decembro 2008, ano III, vol. II, num. 06, páxinas 173-190. In: http://dialnet.unirioja.es/servlet/articulo?codigo=2962813 Acessado em 24/03/2012

12. MACEDO. A.C. 1993. Produção de Mudas em viveiros florestais: espécies nativas. São Paulo. Fundação Florestal, 17p.

13. MARANHÃO, R. 2006. Implementação de bosques e viveiros de espécies nativas do cerrado nos espaços escolares: limites e potencialidades. Dissertação (Mestrado em Ciências Florestais) - Universidade de Brasília.

14. MAZZINI, E. De lixo em lixo, em Presidente Prudente (SP). Novas áreas, velhos problemas. Presidente Prudente: Faculdade de Ciências e Tecnologia, Universidade Estadual Paulista, 1997. p.96 (monografia de Bacharelado).

15. PAIVA, H.N.; GOMES, J.M. (2000). Viveiros Florestais. Viçosa: Universidade Federal de Viçosa. 69p.

16. REIS, A., CARMO, L.; NISHIOKA, I. Logística reversa e práticas correntes no setor de reciclagem. 2008. Disponível em: <http://www.latec.uff.br/cneg/documentos/anais_ cneg4/t7_0080_0050.pdf.> Acesso em 09/02/2012

17. RIOS, C. Lixo e cidadania: um estudo sobre catadores de recicláveis em Divinópolis-MG Dissertação (mestrado em Educação, Cultura e Organizações Sociais) - Universidade do Estado de Minas Gerais, Fundação Educacional de Divinópolis. 2008

18. SANTOS, H.; BORGES, A.; CÂNDIDA, ANA; FEHR, M. Educação Ambiental e Resíduos Sólidos em Araguari/MG, 2010.2 Disponível em: <http://www.catolicaonline.com.br/revistadacatolica/artigosv2n3/11-Geografia.pdf.> Acesso em: 23/02/2012 
19. W. ; MORTIMER, E. Uma análise de pressupostos teóricos da abordagem C-T-S (Ciência-Tecnologia-Sociedade) no contexto da educação brasileira. Ensaio: pesquisa em educação em ciências, v. 2, n. 2, p. 133-162, 2000.

20. W. ; SCHNETZLER, R. Educação em química: compromisso com a cidadania. 3a ed. ljuí: Editora da UNIJUÍ, 2003. v.1 144p.

21. SANTOS, F.A.S.; PARDO, M.B.L. O papel do projeto sala verde na ufs e a concepcoes de edu pdf. In: V Colóquio Internacional "Educação e Contemporaneidade", São Cristóvão, SE, 21 a 23/09/2011. Disponível em: http://ebookbrowse.com Acesso em: 19/03/2012

22. SOARES, L.; SALGUEIRO, A.; GAZINEU, M. Educação ambiental aplicada aos resíduos sólidos na cidade de Olinda, Pernambuco - um estudo de caso. Centro de Ciências e Tecnologia, Universidade Católica de Pernambuco. Revista Ciências \& Tecnologia. Ano 1 n. 1 julh-dez 2007 p.1-9

23. SOUZA, R. "Uma experiência em Educação Ambiental: Formação de valores sócioambientais" Dissertação de Mestrado, Departamento de Serviço Social da PUC- Rio, 2003.

24. THOMAZ-JÚNIOR, A. A reinserção do lixo na sociedade do capital: uma contribuição ao entendimento do trabalho na catação e na reciclagem In: Dinâmica Geográfica do Trabalho no Século XXI : (Limites Explicativos,Autocrítica e Desafios Teóricos) - São Paulo: [s.n], 2009. P.142

25. TOMAZELLO, M. G. O que se entende por Educação Ambiental? Disponível em: < http://educar.sc.usp.br/biologia/cp/Piracicaba/educacao.htm> 23/02/2012

26. VALLE, C. E. Qualidade Ambiental: ISO 14000. 4. ed. Revista e Ampliação, São Paulo: SENAC, 2002. $193 \mathrm{p}$.

27. VergarA S. C. Projetos e Relatórios de Pesquisa em Administração. 5 ed. São Paulo:Atlas, 2004.

28. ZANETI, I. Educação ambiental, resíduos sólidos urbanos e sustentabilidade. Um estudo de caso sobre o sistema de gestão de Porto Alegre, RS. 176 p. (UnB-CDS, Doutor, Política e Gestão Ambiental, 2003). Tese de Doutorado - Universidade de Brasília. Centro de Desenvolvimento Sustentável. 